\title{
Cross calibration of INSAT 3A CCD channel radiances with IRS P6 AWiFS sensor
}

\author{
S K Singh ${ }^{1, *}$, B K Bhattacharya ${ }^{1}$ and A V Kulkarni ${ }^{1,2}$ \\ ${ }^{1}$ Space Applications Centre, Ahmedabad 380 015, India. \\ ${ }^{2}$ Current address: Indian Institute of Science, Bangalore 560 012, India. \\ *Corresponding author.e-mail: sushil@sac.isro.gov.in
}

Indian National Satellite (INSAT) 3A was launched in the year 2003 with communication and remote sensing payloads. The later payloads contain very high resolution radiometer (VHRR) and charge coupled devices (CCD) camera. In this paper, post-launch calibration of INSAT 3A CCD is discussed. A cross radiometric calibration was carried out with well calibrated advanced wide field of view sensor (AWiFS) of Indian Remote Sensing Satellite (IRS P6). Three concurrent scenes of December, January and February were used in this study. Calibration was carried out under different land cover classes such as snow, vegetation, forest, water and cloud. Regression analysis suggests correlation coefficient of $0.95,0.92$ and 0.60 for Red, NIR and SWIR channels with slope values 1.839, 1.589 and 2.232, respectively. New calibration coefficients were used to estimate at-sensor radiance and reflectance in all the three channels. Dynamic range of reflectances was found to be improved by using new calibration coefficients. Normalized difference snow index and vegetation index (NDSI and NDVI) have shown an improvement with new coefficients and were found closer to represent in situ data of different land covers and cloud.

\section{Introduction}

Mapping and monitoring of vegetation dynamics and snow cover are important for a number of Earth resources applications and climate change studies. Remote sensing (polar and geostationary) satellites provide synoptic spectral information for snow cover and vegetation at regular temporal interval (Hall et al. 1995; Matson et al. 1986; Romanov et al. 2003; Fensholt et al. 2006; Kulkarni et al. 2006; Navalgund et al. 2007; Oyoshi et al. 2008).

INSAT series of Indian geostationary satellites was conceived to meet the operational needs of meteorology and weather services besides those related to communication and broadcasting (Joshi et al. 2003). INSAT 3A was flown in 2003 as a combination of meteorological and communication satellite applications. For meteorological observations, INSAT-3A carries a three channel very high resolution radiometer (VHRR) with $2 \mathrm{~km}$ resolution in the visible channel and $8 \mathrm{~km}$ resolution in thermal infrared and water vapour channels (Padmanabhan et al. 2004). In addition, INSAT$3 \mathrm{~A}$ also carries a charge coupled device (CCD) camera which operates in the visible, near infrared (NIR) and short wave infrared (SWIR) channels providing a spatial resolution of $1 \mathrm{~km}$ (table 1 ). INSAT 3A VHRR has been extensively used to generate different operational products like atmospheric motion vector (AMV), water vapour (WV), upper tropospheric humidity (UTH), etc., under space meteorology programme of India (Jayaraman et al. 2007). INSAT 3A CCD narrowband optical data are meant for regular and rapid assessment of terrestrial ecosystems especially vegetation (Bhattacharya et al. 2008) and snow cover monitoring. The temporal evolution of normalized

Keywords. INSAT 3A CCD; IRS P6-AWiFS; radiance; calibration. 
Table 1. Sensor characteristics of INSAT $3 A$.

\begin{tabular}{lllc}
\hline & & \multicolumn{1}{c}{$\begin{array}{c}\text { Wavelength } \\
\text { range }(\mu \mathrm{m})\end{array}$} & $\begin{array}{c}\text { Spatial } \\
\text { resolution } \\
(\mathrm{km})\end{array}$ \\
\hline CCD & Visible & $0.63-0.69$ & 1 \\
& NIR & $0.77-0.89$ & 1 \\
SWIR & $1.55-1.69$ & 1 \\
& FOV & $10^{\circ} \times 10^{\circ}$ & \\
& & $($ Normal frame $)$, & \\
& & $6250 \times 6250 \mathrm{~km}{ }^{2}$ & \\
& Time of overpass & $0500 \mathrm{GMT}$ & \\
\multicolumn{2}{c}{ considered } & $(1030 \mathrm{LMT})$ & \\
\hline
\end{tabular}

GMT: Greenwich Mean Time; LMT: Local Mean Time.

difference vegetation index (NDVI) and normalized difference snow index (NDSI) require to be operationally generated. The multi-spectral optical channel data at $1 \mathrm{~km}(<1 \mathrm{~km}$ at nadir) from INSAT 3A CCD are unique in the world to be used for terrestrial studies from geostationary platform. The INSAT 3A CCD resolution is also better than average sampling distance $(\sim 3 \mathrm{~km})$ of Meteosat Second Generation (MSG) optical data $(1 \mathrm{~km}$ at for visible region). It has been found that the diurnal multi-spectral optical data from geostationary sensor increase the availability of cloud free data as compared to high repeat wide view polar orbiting data such as from MODIS, SPOT-VEGETATION (Fensholt et al. 2006).

The accuracy of quantitative estimates of any geophysical and biophysical products from satellite remote sensing data primarily depends on radiometric calibration. Satellite sensors are a complex system of electronics. During their lifespan, sensor faces a gradual degradation and requires timely calibration for correct and reliable scientific data. The working group on calibration and validation (WGCV) of the International Committee on Earth Observation Satellites (CEOS) defines remote sensing calibration as the process of quantitatively defining the system response to known controlled signal inputs (Belward 1999). Pre-launch instrument characterization, on-board calibration, vicarious calibration and cross-calibration between instruments are all critical components of a calibration system. Pre-flight calibration is a term defined to calibrate the remote sensing devices in laboratory prior to sending sensor into space. Calibration of detector elements may change in space due to variations in the space environment surrounding the sensor that leads to slow deterioration of the electronic system. Gabriel et al. (1997) have briefly reviewed space environment and their effects on low earth orbit (LEO) remote sensing instruments. The long term effects of radiation on sensitive detectors (diode array and CCDs) need to be continuously evaluated in light of the development of higher sensitivity and the need for greater long term stability. In vicarious calibration techniques, post-launch calibration data have to be obtained over natural or artificial sites on the Earth's surface. Different targets for post-launch vicarious calibration like ocean, deserts, high altitude cloud, moon, etc., have been used. Rao et al. (1999) have discussed the post-launch calibration of meteorological satellite sensors of AVHRR and GOES satellite of visible and near-infrared sensors. The post-launch calibration for coarser $(>1 \mathrm{~km})$ resolution radiometry from meterological satellite requires large homogeneous land cover such as desert. The Libeyan and Saharan deserts are used for calibrating AVHRR sensors. Cross calibration method was used to calibrate if the spectral coverage of the two instruments are overlapping. Such two instruments could look same objects on the ground and a comparative calibration could be exercised. In cross calibration, spectral coverage and co-registration could influence the calibration coefficients. Time difference and IFOV are the other factors that can affect the cross calibration. If selected ground targets are homogeneous, these errors will not be so significant. It was also found that the cross calibration error was less than $3.72 \%$ for the field campaign at Ivanpah Playa (Arai 1999). INSAT 3A CCD does not have onboard calibration facility. Indian current polar orbiting satellite IRS P6 carries advanced wide field sensor (AWiFS) with similar optical channels as INSAT 3A CCD but with high spatial resolution $(\sim 56 \mathrm{~m})$. In-flight calibration data of each sensor are available prior to launch and are monitored after launch periodically. The ground-measured feature radiance value for all bands was compared with at-sensor radiance value for quantifying relative response of all cameras with a good correlation (Manjunath and Muralikrishnan 2008; Palsule et al. 2008). AWiFS sensor is being regularly calibrated over known targets at Chharodi site (Gujarat, India) in the absence of onboard calibration. The objectives of the present study are:

- to cross-calibrate at-sensor radiances of INSAT 3A multi-spectral CCD optical channels with calibrated radiances from AWiFS and

- to investigate the effect of cross calibration on snow and vegetation indices.

\section{Datasets used and study region}

Three individual scenes from January, February and March for each sensor were used. Concurrent clear sky satellite overpasses (at 0500 GMT) over 
India on 23 January 2007, 16 February 2007 and 26 March 2007 for INSAT 3A CCD and AWiFS data were selected. The study area encompasses spatial extent $\left(22^{\circ}-37^{\circ} \mathrm{N}, 69^{\circ}-94^{\circ} \mathrm{E}\right)$ which includes different land cover classes over northern India such as snow, agriculture, bare soil, forest, cloud and water bodies. However, Chharodi site (routinely calibrated site for AWiFS sensor), is not considered in the present analysis. In addition, INSAT 3A CCD data on 5 March 2007 was also used in the study to compare the effect of pre-launch and post-launch calibration coefficients.

\section{Sensor characteristics}

In IRS series, an advanced satellite Resourcesat-1 (IRS P6) was launched in October 2003 with polar satellite launch vehicle by Indian Space Research Organization (ISRO). The satellite contains three sensors such as LISS IV, LISS III and AWiFS which have been extensively used in different natural resource applications (Oza and Bhanderi 2004; Kulkarni et al. 2006). The sensor details including spectral channels, resolutions, etc., are summarized in table 1 for INSAT 3A CCD and in table 2 for AWiFS. The latter carries four bands in visible, NIR and SWIR regions with a swath of $740 \mathrm{~km}$ whereas INSAT 3A CCD carries three channels in visible, NIR and SWIR regions covering a $10^{\circ} \times 10^{\circ}$ normal frame mode scanning covering $6250 \mathrm{~km}^{2}$ area in about 25 minutes. The AWiFS and INSAT 3A CCD have similar spectral channels in visible, NIR and SWIR regions. Table 2 shows the major performance parameters of AWiFS sensor of Resourcesat-1 satellite. Data quality evaluation showed that the Resourcesat-1 satellite has met all the specifications of the mission.
Chharodi site was developed for carrying out controlled experiments for sensor calibration/ evaluation with extensive analysis of satellite data and planned for operational calibration/validation activity for Indian Remote Sensing sensors (Shukla and Nair 2002). AWiFS sensor has been routinely calibrated over Chharodi site at Sanand in Gujarat (India) maintaining flat uniform area, stability of surface reflectance, identified area in satellite image and easy accessibility for conducting experiment. The calibration analysis was carried out and the recent calibration data showed less than $2 \%$ degradation for LISS IV and LISS III sensors and 3\% degradation for AWiFS sensor over a period of 3 years (Manjunath and Muralikrishnan 2008). Both INSAT 3A CCD and AWiFS sensor have 10bit radiometric resolution but the spatial resolutions are $1 \mathrm{~km}$ and $56 \mathrm{~m}$, respectively. Figure 1 shows the relative spectral response (RSR) of both the sensors with their extra-terrestrial bandpass irradiances.

\section{Methodology}

Since the magnitude of atmospheric perturbations on spectral channels over the same bandwidth for the AWiFS and INSAT 3A CCD coverage are same, the calibrated AWiFS at-sensor radiances were used to cross-calibrate the INSAT 3A CCD at-sensor radiances for different coregistered and collocated targets. 'At-sensor radiance' is the top of the atmosphere radiance detected by sensor after applying sensor calibration coefficients. The time for INSAT 3A CCD data was chosen at 10:30 am (table 1). The satellite equatorial crossing time for AWiFS was 10:30 am \pm 5 min (table 2). The land targets included low reflecting

Table 2. Major performance parameters of AWiFS camera (Kirankumar 2003).

\begin{tabular}{|c|c|c|c|c|c|}
\hline \multirow{2}{*}{$\frac{\text { Sl. no. }}{1}$} & \multirow{2}{*}{$\begin{array}{l}\text { Parameters } \\
\text { Ground sampling distance (meter) }\end{array}$} & & \multicolumn{3}{|c|}{ Value } \\
\hline & & & & & \\
\hline & Across track & \multicolumn{4}{|l|}{56 (nadir) } \\
\hline & Along track & \multicolumn{4}{|c|}{70 (off-nadir) } \\
\hline & & \multicolumn{4}{|c|}{66 for an integration time of $9.96 \mathrm{msec}$} \\
\hline 2 & Swath (w/o earth curvature effect) & $740 \mathrm{~km}$ & & & \\
\hline \multirow[t]{2}{*}{3} & Bands $(\mu \mathrm{m})$ & B2 & B3 & B4 & B5 \\
\hline & & $0.52-0.59$ & $0.62-0.68$ & $0.77-0.86$ & $1.55-1.70$ \\
\hline 4 & Quantization (Bits) & \multicolumn{4}{|l|}{10} \\
\hline 5 & Signal to noise ratio@ saturation radiance & \multicolumn{4}{|c|}{$>512$ (for all bands) } \\
\hline \multirow[t]{2}{*}{6} & \multirow[t]{2}{*}{ Radiance setting (mw $\left./ \mathrm{cm}^{2} / \mathrm{sr} / \mu \mathrm{m}\right) @ 100 \%$ albedo } & $\mathrm{B} 2$ & B3 & B4 & B5 \\
\hline & & 53 & 47 & 31.5 & 7.5 \\
\hline \multirow[t]{2}{*}{7} & Square wave response $(\%)$ & $\mathrm{B} 2$ & B3 & B4 & B5 \\
\hline & & $>30$ & $>30$ & $>20$ & $>20$ \\
\hline 8 & Band to band registration (pixel) & \multicolumn{4}{|l|}{$\leq \pm 0.25$} \\
\hline 9 & Instantaneous cross track FOV & \multicolumn{4}{|c|}{0.0000717 (in radians) } \\
\hline 10 & Time of pass & \multicolumn{4}{|c|}{$10.30 \mathrm{am} \pm 5 \mathrm{~min}$} \\
\hline
\end{tabular}



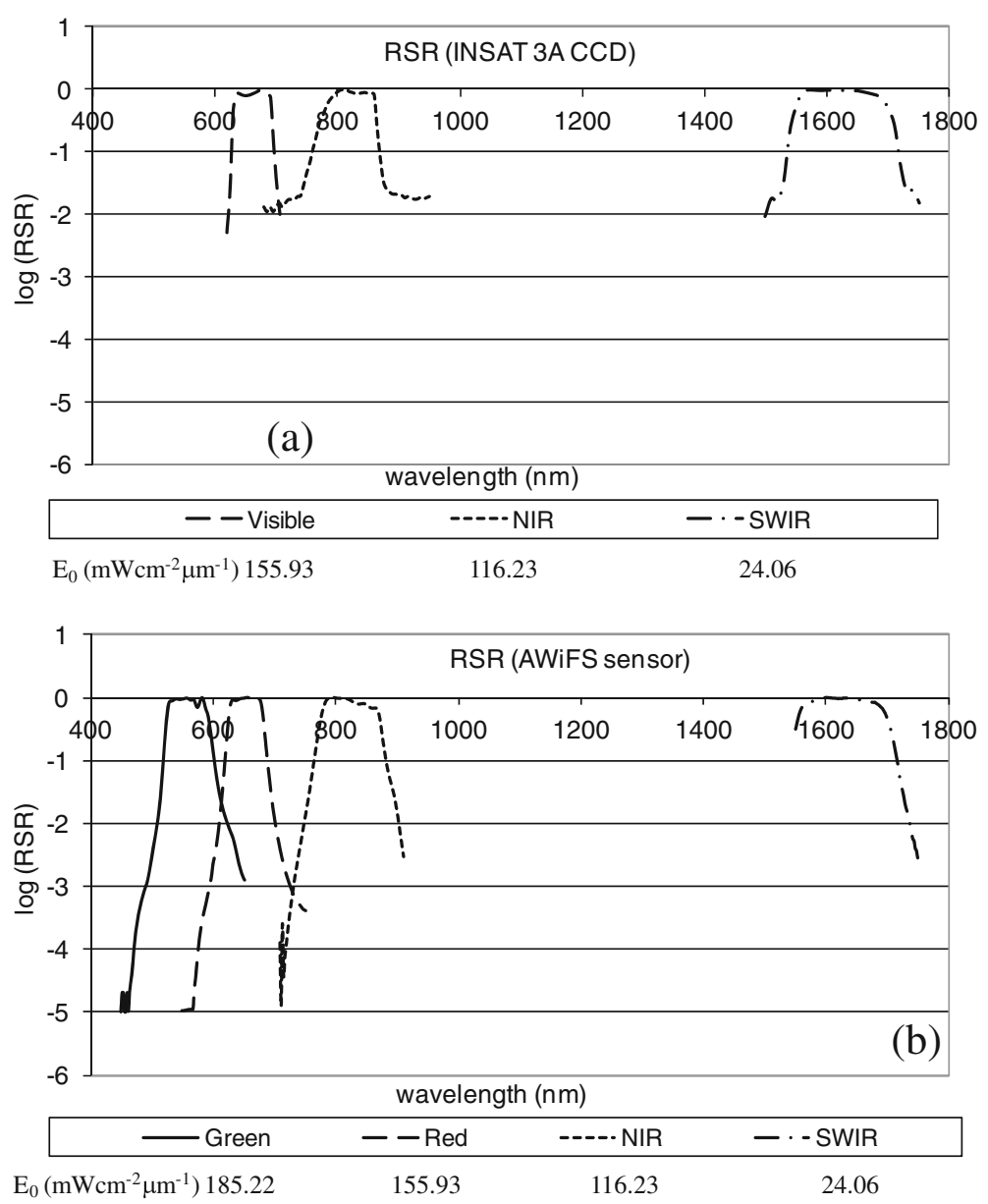

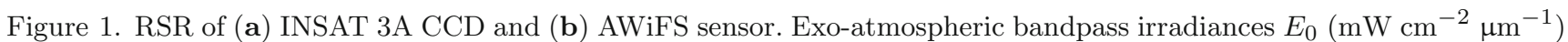
has been given for all channels of both the sensors respectively.

surface such as water to high reflecting surface such as snow and cloud. The other intermediate reflecting surfaces are agriculture, bare soil and forest. At-sensor radiances were computed for all the three optional channels using ground-based calibration coefficients for AWiFS and pre-flight coefficient for INSAT 3A CCD. The at-sensor apparent reflectance (TOA reflectance) was computed assuming a lambertian surface and RSRweighted exo-atmospheric bandpass irradiances $\left(E_{0}(\lambda)\right)$. The INSAT $3 \mathrm{~A}$ CCD NDSI and NDVI were computed from TOA reflectance before and after cross-calibration.

The at-sensor radiance and TOA apparent reflectance for both the sensors were computed using equations (1) and (2) as follows:

$$
\begin{gathered}
L_{\lambda}=\frac{\left(L_{\max \lambda}-L_{\min \lambda}\right) D N_{\lambda}}{\left(D N_{\max \lambda}\right)}+L_{\min \lambda} \\
R_{\lambda}=\frac{\pi L_{\lambda}}{E_{0}(\lambda) \cos \theta}
\end{gathered}
$$

where $D N_{\lambda}, D N_{\max \lambda}, L_{\max \lambda}, L_{\min \lambda}, E_{0}(\lambda), \theta$, $L_{\lambda}$ and $R_{\lambda}$ are digital number, maximum $D N$, saturation radiance $\left(\mathrm{mW} \mathrm{cm} \mathrm{cm}^{-2} \mathrm{sr}^{-1} \mu \mathrm{m}^{-1}\right)$, minimum radiance $\left(\mathrm{mW} \quad \mathrm{cm}^{-2} \mathrm{sr}^{-1} \mu \mathrm{m}^{-1}\right)$, exoatmospheric bandpass irradiance $\left(\mathrm{mW} \mathrm{cm}^{-2} \mu \mathrm{m}^{-1}\right)$, solar zenith angle, radiance at wavelength $\lambda$ and reflectance at wavelength $\lambda$, respectively.

Normalized difference vegetation index (NDVI) and normalized difference snow index (NDSI) were computed using equations (3) and (4), respectively (Fensholt et al. 2006; Kulkarni et al. 2006)

$$
\mathrm{NDVI}=\frac{\left(\text { reflectance }_{\mathrm{NIR}}-\text { reflectance }_{\mathrm{RED}}\right)}{\left(\text { reflectance }_{\mathrm{NIR}}+\text { reflectance }_{\mathrm{RED}}\right)}
$$

$\mathrm{NDSI}=\frac{\left(\text { reflectance }_{\mathrm{VISIBLE}}-\text { reflectance }_{\mathrm{SWIR}}\right)}{\left(\text { reflectance }_{\mathrm{VISIBLE}}+\text { reflectance }_{\mathrm{SWIR}}\right)}$

Here, Red wavelength represents to VIS band region of INSAT 3A CCD. Figure 2(a) showed the 


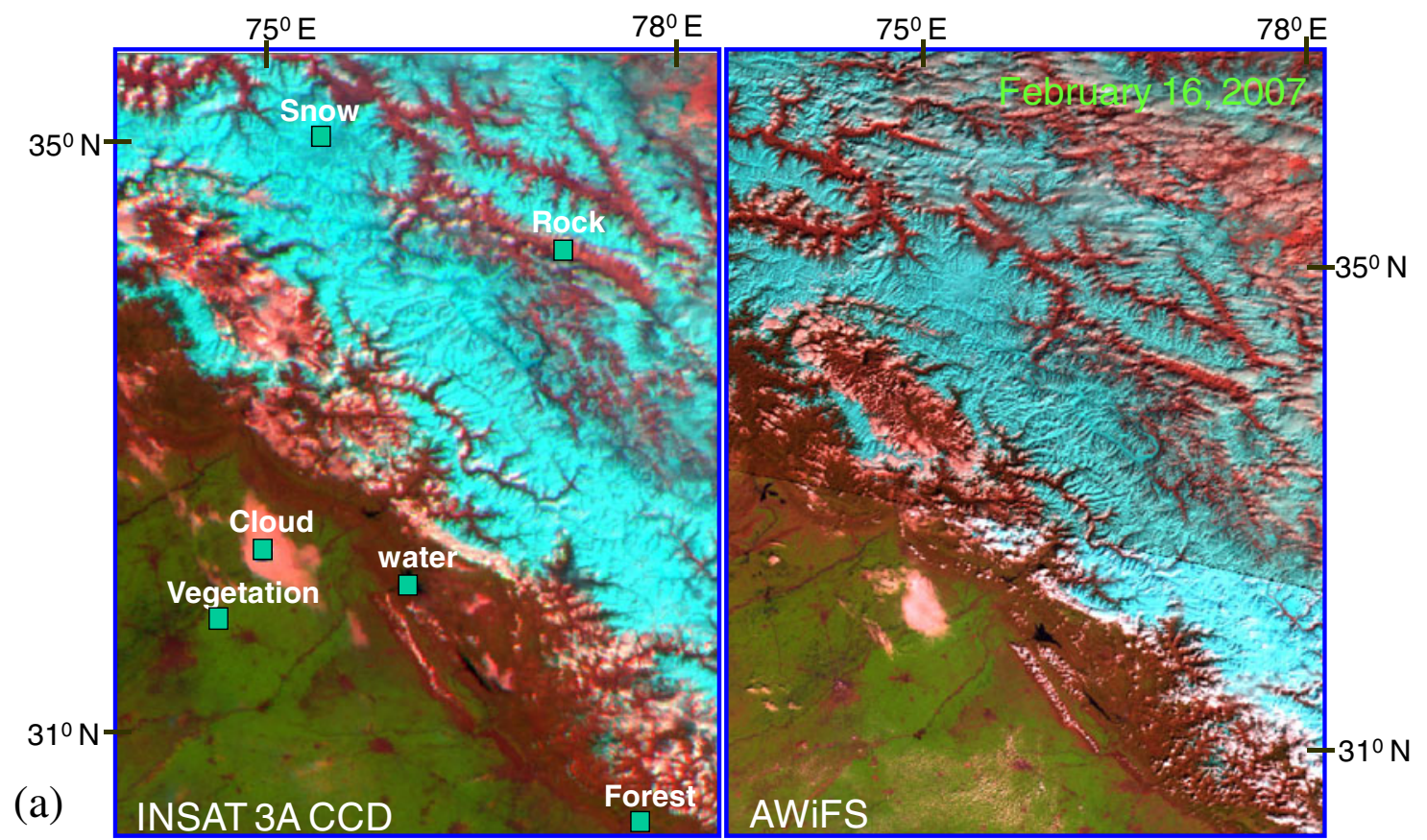

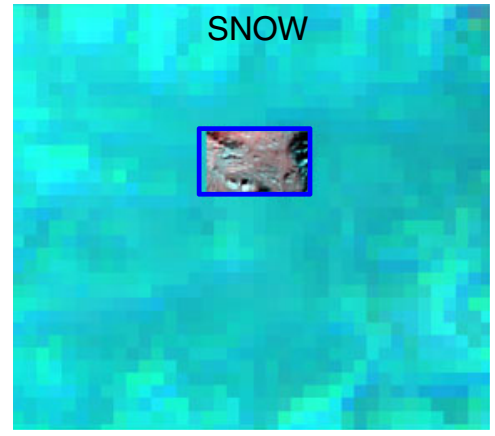

(b) SnOw:

AWiFS: $136 \times 85$

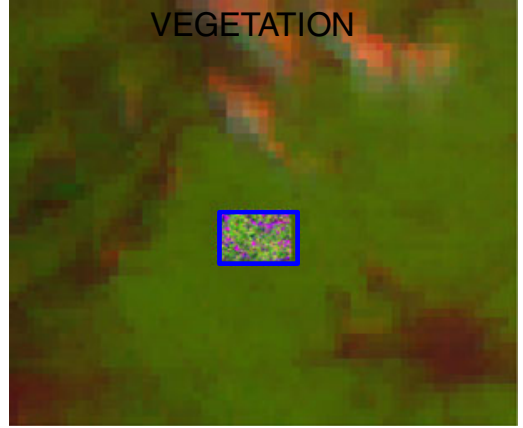

Vegetation:

INSAT: $10 \times 7$

AWiFS: $132 \times 89$

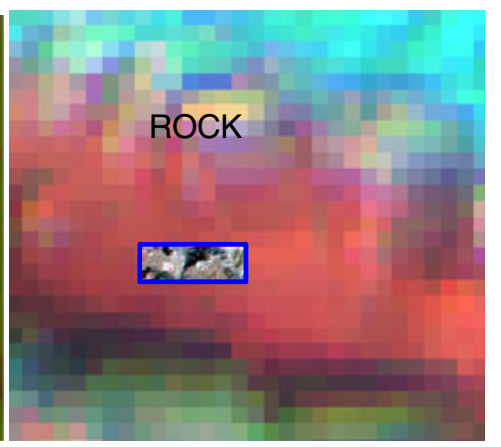

Rock:

INSAT: $7 \times 3$

AWiFS: $110 \times 40$

Figure 2. (a) INSAT 3A CCD and AWiFS FCC images of February 16, 2007 over the study region showing different land targets; (b) Selected collocated subset area of different land cover classes. For example, number of pixels on 16 February 2007: snow (INSAT $9 \times 6$; AWiFS $136 \times 85$ ); rock (INSAT $7 \times 3$; AWiFS $110 \times 40$ ); cloud $($ INSAT $14 \times 11$; AWiFS $195 \times 50$ ); vegetation (INSAT $10 \times 7$; AWiFS $132 \times 89$ ); water $($ INSAT $5 \times 3$; AWiFS $63 \times 36$ ) and forest (INSAT $3 \times 2$; AWiFS $31 \times 16)$.

co-registered image of INSAT 3A CCD and AWiFS of 16 February 2007 over the study region. With the help of band combinations, different land cover classes such as snow, vegetation, forest, rock, cloud, etc., were identified in all the images as depicted in figure 2(a). Average radiance values of common homogeneous subset of collocated targets were calculated for all INSAT pixels to all respective AWiFS pixels of one object. This accounts for the spatial heterogeneity introduced due to the difference in spatial resolutions of both the sensors. A subset of all classes consisting same area were extracted from the radiance images as shown in figure 2(b). The average at-sensor radiances for each class were computed for each channel
(Visible, NIR and SWIR). The radiances from both AWiFS and INSAT 3A CCD were subsequently plotted for all the three channels. The linear regression was performed for individual channels between calibrated AWiFS and INSAT 3A CCD at-sensor radiances with pre-launch calibration. Central wavelength of INSAT 3A CCD and AWiFS were computed (table 3) using Palmer approach which incorporates the minimum and maximum wavelength of bandwidth $\left(\lambda_{\min }\right.$ and $\left.\lambda_{\max }\right), \mathrm{RSR}$ and effective bandwidth $(\Delta \lambda)$ (Liang 2004). Radiometric data of different objects in parts of the Himalayas were used for comparison after deriving radiometric quantities and indices of the respective objects. 
Table 3. Comparison of central wavelengths of INSAT $3 A C C D$ and AWiFS.

\begin{tabular}{lccc}
\hline Channel & $\begin{array}{c}\text { INSAT 3A CCD } \\
\left(\lambda_{\text {centre }} \text { in } \mu \mathrm{m}\right)\end{array}$ & $\begin{array}{c}\text { AWiFS } \\
\left(\lambda_{\text {centre in } \mu \mathrm{m})}\right.\end{array}$ & $\begin{array}{c}\text { Absolute } \\
\text { difference }(\mathrm{nm})\end{array}$ \\
\hline Green channel & - & 0.556 & - \\
Red channel & 0.661 & 0.652 & 8.9 \\
Near infrared channel & 0.821 & 0.816 & 5.0 \\
Short wave infrared channel & 1.618 & 1.625 & 7.0 \\
\hline
\end{tabular}

\section{Results and discussion}

\subsection{Calibration of INSAT 3A CCD channels}

The calibration curves have been shown in figure 3 for all the channels. The regression analysis between corresponding AWiFS and INSAT 3A CCD channels showed linear relations with high $R^{2}$ of 0.96 for visible channel $(0.63-0.69 \mu \mathrm{m})$ and of 0.92 for NIR $(0.77-0.89 \mu \mathrm{m})$ channels with 16 datasets. The INSAT 3A CCD SWIR channel showed severe sensor degradation with low $R^{2}$ of 0.60 . The slope values after cross calibration for Visible, NIR and SWIR channels were found to be $1.839,1.589$ and 2.232 , and intercepts as -5.803 , -4.950 and -0.481 , respectively. The linear relations were further used to compute CCD at-sensor radiances, TOA apparent reflectances, NDVI and NDSI using equations (1), (2), (3) and (4), respectively with independent INSAT 3A CCD dataset on 5 March 2007 (figure 4). It was observed that central wavelength difference varies from 5-9 nm for INSAT $3 \mathrm{~A}$ and AWiFS and is not significant (table 3 ). It rules out any effect of shift in central wavelength on differences in at-sensor radiances between two sensors.

\subsection{Effect of cross-calibration on snow and vegetation indices}

The old and new calibrated CCD channel radiances, TOA apparent reflectances and indices extracted over different land cover classes are given in table 4. Ground-measured snow indices (NDSI) for the selected land cover classes computed over Himalayan region are also shown in table 4 for comparison. A comparison of indices (NDSI and NDVI) with new and old calibration coefficients in table 4 showed an improvement towards fieldbased observations of respective land cover classes except water. An improvement on dynamic range of reflectance with old calibration (15-75\%) and new calibration (10-110\%) coefficient were found in the visible channel. Table 4 showed that the reflectance values for Visible, NIR and SWIR for
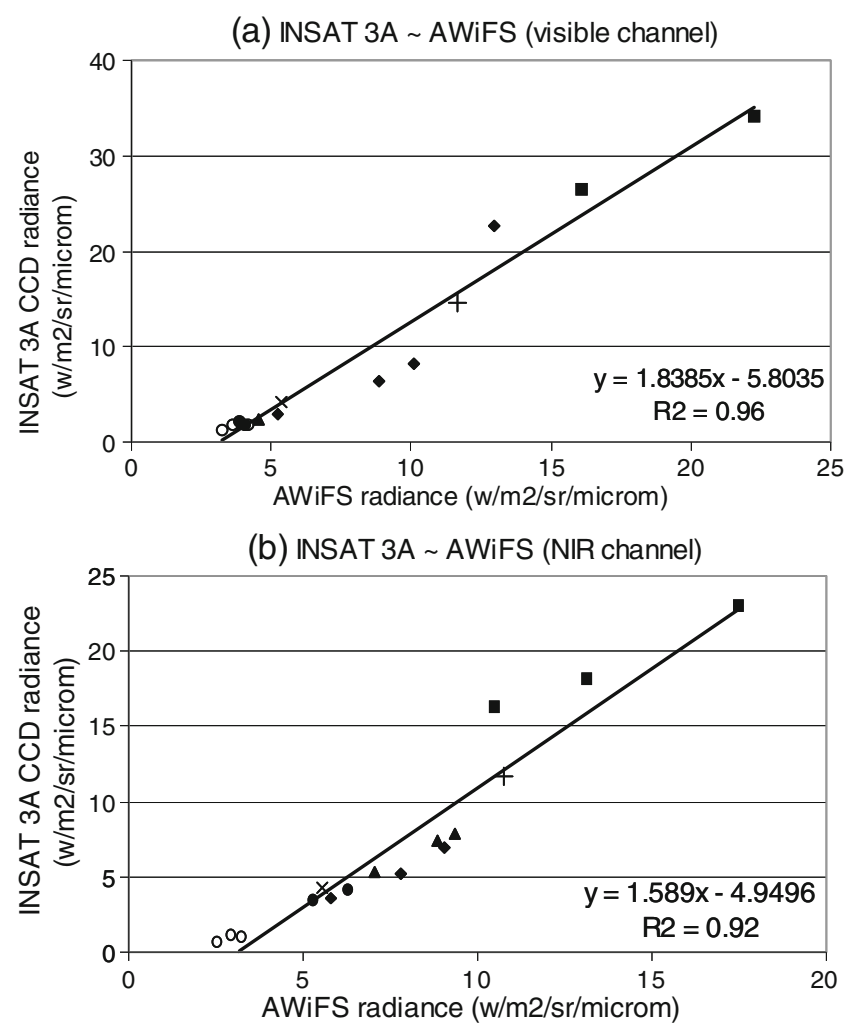

(c) INSAT 3A AWIFS (SWIR channel)

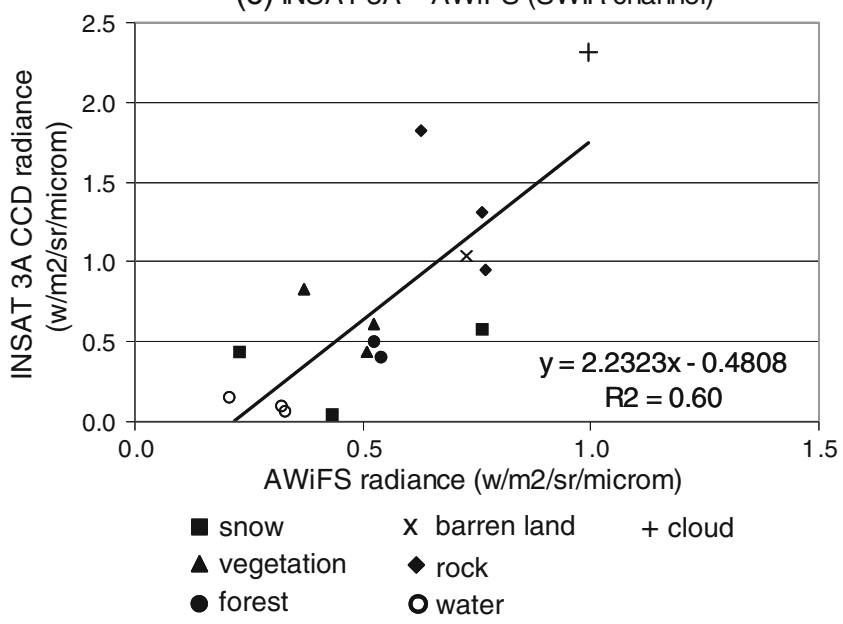

Figure 3. Regression fits between INSAT 3A CCD and AWiFS at-sensor radiances for (a) visible channel, (b) NIR channel and (c) SWIR channel. 

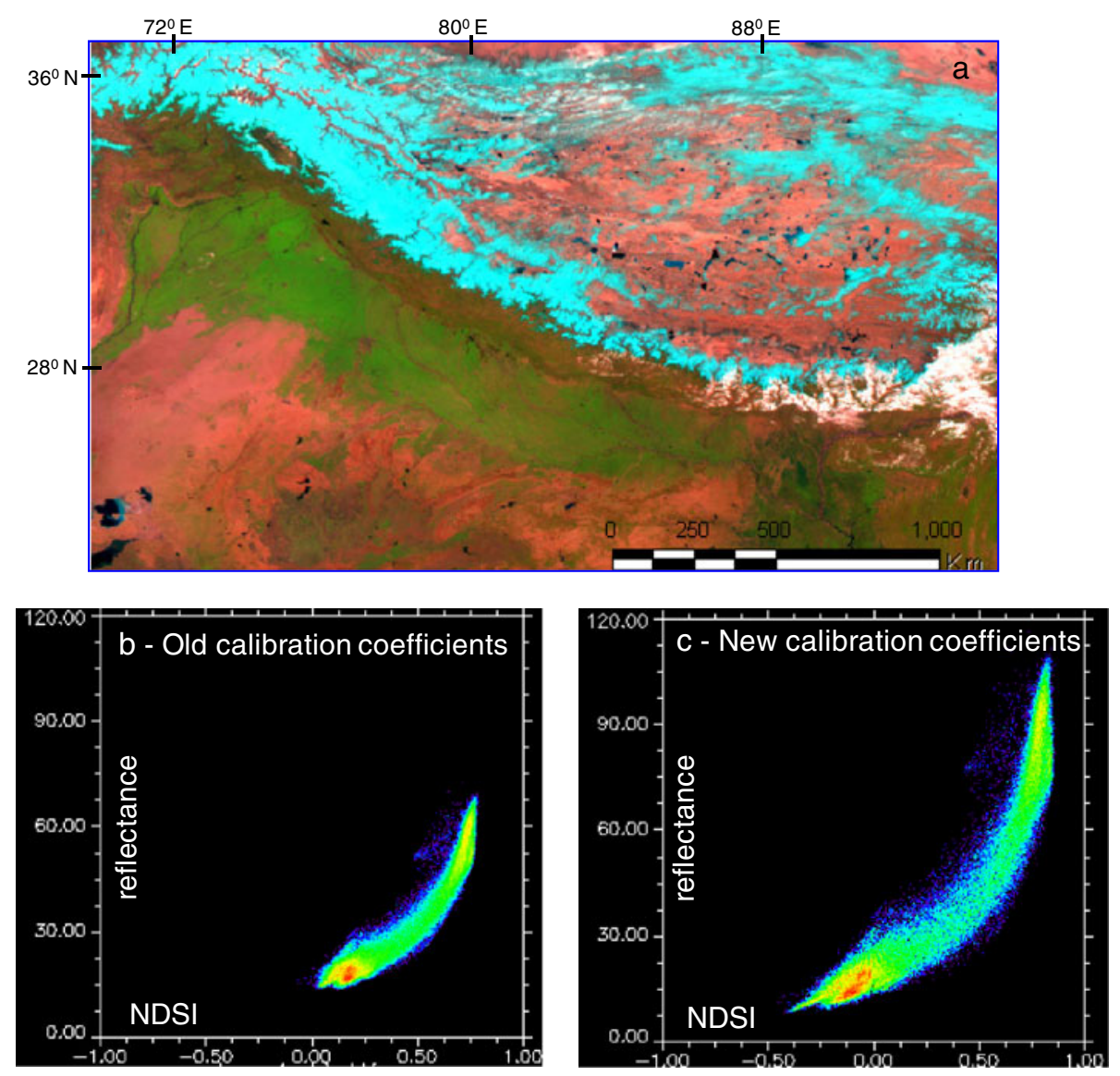

Figure 4. Comparison of INSAT 3A CCD data (5 March 2007) with old and recalibrated coefficients. (a) INSAT 3A CCD FCC of 5 March 2007; (b) scatterplots of NDSI (X-axis) and TOA reflectances of red channel (Y-axis) of old and (c) new calibration coefficients of INSAT image.

selected land cover classes have been modified with an improved dynamic range. High reflecting objects such as snow and cloud have shown a significant improvement from old TOA reflectance to new TOA reflectance computation. In agriculture and forest land cover classes, visible channel TOA reflectance have shown a reduction whereas SWIR channel has shown an increase. SWIR channel was also found to be increased for desert and rock land cover classes. This established that the new coefficients of INSAT 3A CCD data for Visible, NIR and SWIR channels can be used to recalibrate and improve the radiometric quantity for routine applications.

Figure 4(a) showed the INSAT 3A CCD data of 5 March 2007 and figure 4(b) showed the scatterplots of TOA apparent reflectance of visible channel and NDSI using old and new calibration coefficients. Figure 5 showed the histogram of NDSI and NDVI for pre-launch and post-launch calibration. The NDSI and NDVI values were computed using both old and new calibrated coefficients. The NDSI and NDVI dynamic ranges have shown an improvement from $0.0-0.7$ to $-0.45-0.85$ and $0.0-0.50$ to
$-0.10-0.80$, respectively. The NDSI peak has been shifted from 0.1 to -0.25 which showed the dominant presence of non-snow pixels as can be observed in false colour composite (FCC) image. Another broad peak of 0.66 was shifted to 0.71 which is related to snow-covered pixels. NDVI values too have shown a peak shifted towards negative side close to 0.0 . The dynamic range of NDSI and NDVI was found to be improved in Histograms. This redistribution of NDSI and NDVI values would be helpful further to identify different classes of snow and vegetation pixels. It has also been reported that revised calibration coefficients improved the radiometric accuracy and NDVI using Landsat TM data (Chander and Groeneveld 2009). Pandya et al. (2007) have carried out the analysis of spectral characterization of numerous Indian remote sensing sensors and shown the influence of reflectance on NDVI were significant. This highlights the importance of post-calibration to correct the radiometric quantities for better estimation of various indices for natural resources applications. Thus, these new calibration coefficients will help to improve the monitoring of snow 


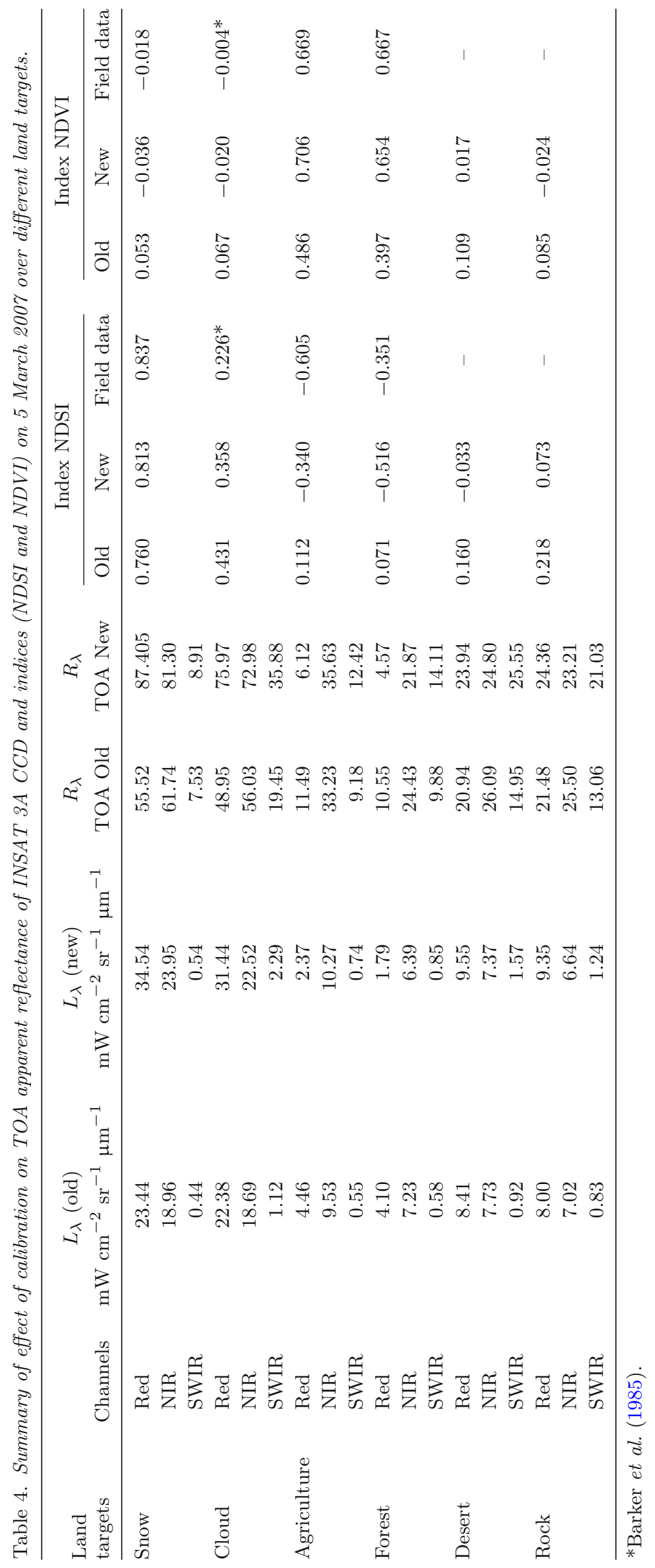



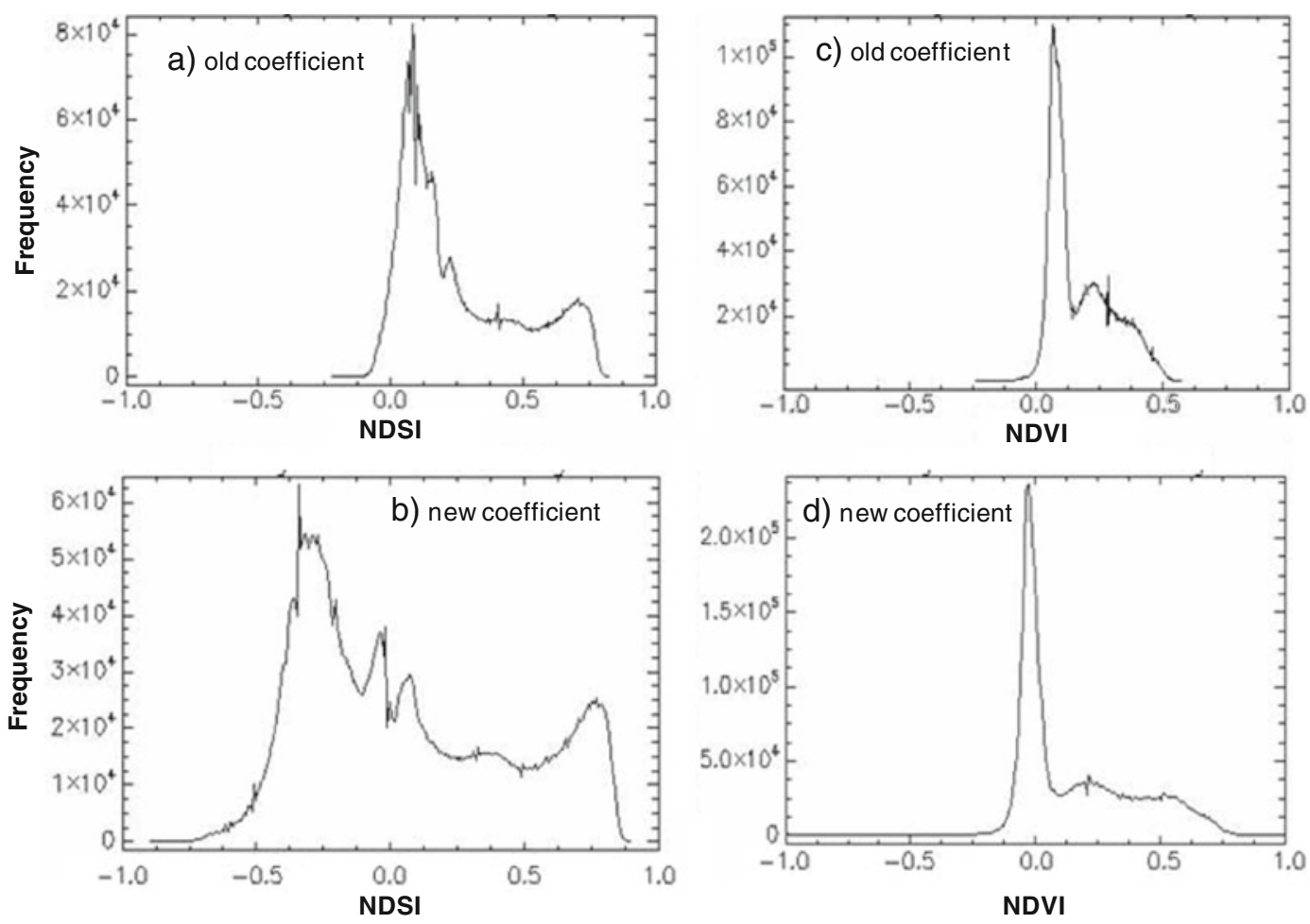

Figure 5. Histograms for NDSI and NDVI from INSAT 3A CCD (5 March 2007 at 0500 GMT) using old and new calibration coefficients. ( $\mathbf{a}$ and $\mathbf{b}$ ) shows the distribution of NDSI values with old and new calibrated coefficients whereas (c and $\mathbf{d}$ ) shows the same for NDVI values.

cover and vegetation, and will provide important inputs to model the long term monitoring of natural resources of earth environment.

\section{Conclusions}

This study demonstrates the utility of cross calibration of sensors placed at different satellite platform without on-board calibration facilities. INSAT 3A CCD data in Visible, NIR and SWIR channels were calibrated with coregistered AWiFS data under different land cover classes such as vegetation, forest, barren land, water, snow/ice and cloud. The linear fits have shown good agreements with high $R^{2}$ of 0.95 and 0.92 for Visible and NIR channels along with slope values as 1.839 and 1.589 , respectively and low $R^{2}$ of 0.60 for SWIR channel along with slope value as 2.232 . The low $R^{2}$ could be due to the degradation in SWIR channel while ruling out any possibility due to shift in central wavelength of RSR between the sensors. The new calibration coefficients also showed an improvement in dynamic range of reflectance and indices (NDSI and NDVI) supported by field observations except water. These new calibration coefficients would help to improve applications using INSAT 3A CCD data to compare better temporal dynamics for natural resources applications from geostationary platform.

\section{Acknowledgements}

The authors are thankful to Sh. A S Kirankumar, Director, SAC and Dr P K Pal, Group Director, AOSG for their suggestions during the study. Authors are also grateful to Dr J S Parihar, Deputy Director, EPSA to facilitate the study. Authors would like to thank Dr Ajai, Group Director, MPSG, Dr A S Rajawat, Head, GSD and Dr T J Majumdar, then Head, ESHD for their encouragement and support during the investigations.

\section{References}

Arai K 1999 Error budget analysis of cross calibration method between ADEOS VNIR and OCTS; Adv. Space Res. 23(8) 1385-1388.

Barker D E, Davis R E, Myrick D L and Jones W T 1985 Spectral reflectances of natural targets for use in remote sensing studies; NASA Reference Publication 1139.

Belward A S 1999 International co-operation in satellite sensor calibration: The role of the CEOS working group on calibration and validation; Adv. Space Res. 23 1443-1448.

Bhattacharya B K, Mallick K, Nigam R, Patel N K, Padmanabhan N, Mahammad Sk S, Ramakrishnan R and Parihar J S 2008 A study on land surface radiation budget parameters using KALAPNA-1 VHRR and INSAT$3 \mathrm{~A}$ CCD data for agrometeorological applications; ISRO Scientific Report ISRO/ASP/SAC/01/2008.

Chander G and Groeneveld D P 2009 Intra-annual NDVI validation of the Landsat 5 TM radiometric calibration; Int. J. Rem. Sens. 30(6) 1621-1628. 
Fensholt R, Sandholt I, Stisen S and Tucker C 2006 Analysing NDVI for the African continent using the geostationary meteosat second generation SEVRI sensor; Rem. Sens. Environ. $101212-229$.

Gabriel S B, Spilling D A and Amieux J C 1997 Effects of the space environment on the calibration and performance of remote sensing instruments; Adv. Space Res. 19(9) 1359-1365.

Hall D K, Riggs G A and Salomonson V V 1995 Development of methods for mapping global snow cover using moderate resolution image spectroradiometer data; Rem. Sens. Environ. 54 127-140.

Jayaraman A, Joshi P C and Ramesh R 2007 Developments and achievements in atmospheric sciences and space meteorology in India; Curr. Sci. 93(12) 1779-1790.

Joshi P C, Narayanan M S, Bhatia R C, Manikam B, Kirankumar A S and Jayaraman V 2003 Evolution of Indian satellite meteorological programme; Mausam 54(1) 1-12.

Kirankumar A S 2003 Advanced Wide Field Sensor (AWiFS); SAC Courier 28(2) 3-7.

Kulkarni A V, Singh S K, Mathur P and Mishra V D 2006 Algorithm to monitor snow cover using AwiFS data of Resourcesat for the Himalayan region; Int. J. Rem. Sens. 27(12) 2449-2457.

Liang S 2004 Quantitative remote sensing of land surfaces; Wiley-Interscience, John Willey \& Sons, Inc., 534p.

Manjunath A S and Muralikrishnan S 2008 Geometric and radiometric evaluation of Resourcesat-1 sensors; Int. J. Appl. Earth Observat. Geoinformatics 10 159-164.

Matson M, Roepelewski C F and Varnadore M S 1986 An atlas of satellite derived northern hemisphere snow cover frequency (Washington, DC: National Weather Service).
Navalgund R R, Jayaraman V and Roy P S 2007 Remote sensing applications: An overview; Curr. Sci. 93(12) 1747-1766.

Oyoshi K, Takeuchi W and Yasuoka Y 2008 http://www. aars-acrs.org/acrs/proceeding/ACRS2007/Papers/TS4.2. pdf (on 06.12.08).

Oza M P and Bhanderi R J (eds) 2004 IRS-P6 early evaluation studies; IRS P6 evaluation team SAC/RESIPA/SR02/Oct 2004, 152p.

Padmanabhan N, Darji N P, Mohammad S, Kayal R and Shukla A P 2004 INSAT-3A/KALPANA data products generation system; SAC/RESIPA/SIPG/DPSD/ TN-12/Dec 2004, 59p.

Palsule S S, Shah B, Paswan G, Sharma A, Garg A, Pandya H, Srivastava S S and Roy S 2008 Resourcesat-1 data quality evaluation system; Int. J. Appl. Earth Observat. Geoinformatics 10 147-158.

Pandya M R, Singh R P, Chaudhari K N, Murali K R, Kirankumar A S, Dadhwal V K and Parihar J S 2007 Spectral characteristics of sensors onboard IRS-1D and P6 satellites: Estimation and their influence on surface reflectance and NDVI; Photonirvachak 35(4) 333-350.

Rao C R N, Chen J, Sullivan J T and Zhang N 1999 Postlaunch calibration of meterological satellite sensors; $A d v$. Space Res. 23(8) 1357-1365.

Romanov P, Tarpley D, Gutman G and Carroll T 2003 Mapping and monitoring of snow cover fraction over North America; J. Geophy. Res. 108(D16 8619) 14-1-14-15.

Shukla A K and Nair P R 2002 Methodology development for in-flight calibration and evaluation of high resolution remote sensing sensors using artificial calibration site, IAPRS \& SIS, 34, part 7, Resource and Environmental Monitoring, Hyderabad, India, pp. 28-34. 